\title{
Analysis of the Hydrochemical Characteristics and the Evolutionary Stages of Brine in Mahai Salt Lake in the Qaidam Basin
}

\author{
Shu-ya $\mathrm{Hu}^{1}$, Quan-sheng Zhao, ${ }^{1, *}$, Jian-wei Zhang ${ }^{1}$, and Jian-lei Chen ${ }^{1}$ \\ ${ }^{1}$ Department of Environmental Science and Engineering, Qingdao University, Qingdao, China \\ ${ }^{2}$ Key Laboratory of Marine Chemistry Theory and Technology, Ministry of Education, Ocean \\ University of China, Qingdao, China
}

\begin{abstract}
The objective of this study was to contribute to the understanding of the hydrochemical processes and evolution of brine in the Qaidam basin, in order to provide a theoretical basis for the application of brine resources in the region. The hydrochemical characteristics and evolutionary stages of brine in Mahai Salt Lake were investigated using factor analysis on brine chemistry data from 109 sampling points. Our results showed that the centre of the Salt Lake has the highest concentration of total dissolved solids (TDS), and the hydrochemical type of brine is chloride-magnesium. The brine at the centre of the lake is at the later stages of mirabilite precipitation, and the content of $\mathrm{K}^{+}$is relatively stable. Comparatively, the hydrochemical type of brine in the slope area of the Salt Lake is $\mathrm{Cl}-\mathrm{Na}-\mathrm{Mg}$, and is at the early stages of brine evolution. It is of guiding significance to further develop and utilize brine resources, especially to evaluate its resource development potential.
\end{abstract}

\section{Introduction}

The chemical composition of groundwater is the product of the long-term interaction of the water with its surrounding environment, such as the atmosphere, surface water, and rocks [1]. The main ion components in groundwater can be used to determine the factors influencing water chemistry, as well as identify the material sources. Therefore, by analysing the main ion composition in groundwater, we can identify the basic processes influencing water chemistry in order to build an understanding of the chemical evolution of groundwater [2]. The study of hydrogeochemistry in arid regions is very important, especially in brine development areas [3], because precipitation is scarce, evaporation is intense and ecological environment is fragile. In particular, the study of brine chemistry can improve our understanding of the formation and evolution characteristics of brine. In recent years, the majority of research into brine chemistry have predominantly focused on brine evolution and ion sources. For example, stable isotope and hydrochemical analyses of groundwater have been analysed in the Gulf Coast Basin, central Australia, the Tecopa Basin in southeastern California, and in uranium deposits and the Ejina Basin in northwest

*Corresponding author: 90shuya@ sina.com 
China, to assess brine genesis and evolution (Eastoe et al., 2001; Dogramaci et al., 2012). In this study, we analyse 109 underground brine samples collected from Mahai Salt Lake in the northeast of the Qaidam Basin, for brine ion content. The evolutionary stage of submarine brine in Mahai Salt Lake was determined through hydrochemical characterization and factor analysis.

\section{Study area and samples}

The Qaidam Basin is located in the northeast of the Qinghai-Tibet Plateau, surrounded by the Altun Mountains, the Qilian Mountains and the Kunlun Mountains. Mahai Salt Lake is located in a small salinization basin in the northeast of the Qaidam Basin (Fig. 1) and is a sub-basin within the Qaidam "alpine deep basin". The study object is a flat, Salt Lake sedimentary plain, with an elevation of approximately 2743-2750 meters. The study area experiences typical inland arid climate; cold and dry. The average annual temperature, rainfall and evaporation is $2.1^{\circ} \mathrm{C}, 29.61 \mathrm{~mm}, 3040 \mathrm{~mm} / \mathrm{yr}$, respectively [4-5]. Brine samples were collected from monitoring wells and production wells in the Mahai Salt Lake at a sampling depth of $0.20-15.43 \mathrm{~m}$.

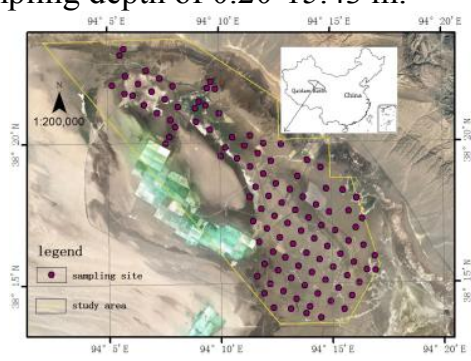

Fig. 1. Study area and the distribution of sampling spots

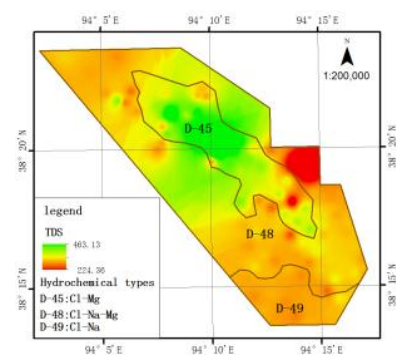

Fig.2. The TDS interpolation map and hydrochemical types of the brine.

\section{Methods}

\subsection{Factor analysis}

Factor analysis is a statistical method used to describe variability among observed, correlated variables in terms of a potentially lower number of unobserved variables called factors. The purpose of factor analysis is to decompose the original variables, and to summarise them into potential "categories". The more relevant indicators are grouped together so that the correlation between different categories of variables is lower (Usunoff et al., 2010). In this study, we apply factor analysis to group together the brines of the same evolutionary stage in Mahai Salt Lake.

Before analysis, the data was standardised so that parameters with low variability would not be masked by parameters of higher variability. This eliminated the influence of different units of measurement, and rendered the data dimensionless. A Kaiser-MeyerOlkin (KMO) test and Bartlett's test were used to check the sampling adequacy and sphericity. The KMO test result was 0.61 and the Bartlett's test result was 1675.433, indicating that the correlation between variables is strong, and that factor analysis can be performed on the data. Factor analysis was performed using SPSS 18.0 statistical software (IBM Brand). 


\subsection{Analytical methods of the samples}

The contents of $\mathrm{Na}^{+}$and $\mathrm{K}^{+}$were determined by atomic absorption spectroscopy. $\mathrm{The}^{\mathrm{Mg}^{2+}}$ and $\mathrm{Ca}^{2+}$ were determined using titration tests according to the guidelines provided for the analysis of salt and brine samples. The $\mathrm{Cl}^{-}$was measured by titration with silver nitrate and using potassium chromate as the indicator. The $\mathrm{SO}_{4}{ }^{2-}$ was determined by barium chloride titration and methyl orange as the indicator. In addition, the total dissolved solids (TDS) were estimated based on the conductivity measurements and the sum of the total analysed dissolved solids (Hu et al., 2018).

\section{Results and analysis}

\subsection{Major ions in Mahai Salt Lake}

Water chemistry statistics of the brine samples in Mahai Salt Lake are shown in Table 1. The cations identified in the brine samples (in decreasing order of concentration) are $\mathrm{Na}^{+}>\mathrm{Mg}^{2+}>\mathrm{K}^{+}>\mathrm{Ca}^{2+}$, with average concentrations of $51.8 \mathrm{~g} / \mathrm{L}, 47.9 \mathrm{~g} / \mathrm{L}, 7.87 \mathrm{~g} / \mathrm{L}$, and $0.550 \mathrm{~g} / \mathrm{L}$, respectively. The anions identified in the samples in decreasing order of concentration are $\mathrm{Cl}^{-}>\mathrm{SO}_{4}{ }^{2-}$, with average concentrations of $214.3 \mathrm{~g} / \mathrm{L}$ and $14.07 \mathrm{~g} / \mathrm{L}$, respectively.

Table 1. Statistical parameters for the chemical compositions of water samples collected in the Mahai Salt Lake.

\begin{tabular}{|c|c|c|c|c|c|c|c|c|c|}
\hline & $\mathrm{p}$ & $\mathrm{K}^{+}$ & $\mathrm{Na}^{+}$ & $\mathrm{Ca}^{2+}$ & $\mathrm{Mg}^{2+}$ & $\mathrm{Cl}^{-}$ & $\mathrm{SO}_{4}{ }^{2-}$ & Densit & TDS \\
\hline $\mathrm{n}=109$ & & & & & & & & & \\
\hline Minimum & 7. & 0.53 & 1.25 & 0.03 & 7.54 & 139.30 & 0.21 & 1.15 & 224.01 \\
\hline Maximum & 9. & 29.39 & 113.70 & 6.18 & 119.30 & 340.50 & 43.53 & 1.33 & 463.25 \\
\hline Mean & 8. & 7.87 & 51.75 & 0.55 & 47.90 & 214.26 & 14.07 & 1.23 & 336.40 \\
\hline SD & 0. & 5.56 & 35.00 & 0.83 & 29.59 & 38.10 & 8.55 & 0.03 & 36.35 \\
\hline
\end{tabular}

The distribution of total dissolved solids (TDS) in Mahai Salt Lake ranges from 224.01$463.25 \mathrm{~g} / \mathrm{L}$. The average TDS is $336.40 \mathrm{~g} / \mathrm{L}$; approximately ten times higher than the concentration of sea water. The brine TDS in the study area was interpolated using inverse distance weighted interpolation. As can be seen from the interpolation (Fig. 2), higher TDS values can be observed in the central part of the study area, and all TDS values exceed $340 \mathrm{~g} / \mathrm{L}$.

\subsection{Hydrochemical classification of brine}

Hydrochemical classification of brine can help to elucidate the chemical composition of groundwater within a region and identify the causes of its variability. Using Shkaliv's water chemistry classification (Wang, 2001), based on the degree of TDS, ion composition and content, we classify our brine water samples into three types: $\mathrm{Cl}-\mathrm{Mg}, \mathrm{Cl}-\mathrm{Na}-\mathrm{Mg}$, and ClNa. Hydrochemical classification of brine in the Mahai Salt Lake shows annular distribution features (Fig. 2). As demonstrated from Fig. 2, the distribution area of $\mathrm{Cl}-\mathrm{Na}$ brines corresponds with lowest TDS, with values $<310 \mathrm{~g} / \mathrm{L}$. In contrast, the distribution area of Cl-Mg brines correlate with highest TDS, showing values > $310 \mathrm{~g} / \mathrm{L}$. Cl-Na-Mg brines however, showed little to no correlation with TDS. 


\subsection{Factor analysis of brine evolution in Mahai Salt Lake}

\subsubsection{Factor analysis}

According to the principle that the eigenvalue is greater than 1, three common factors were selected in this study, with a cumulative variance contribution rate of $81.693 \%$. The eigenvalues of the three factors, their percentage of variance, the cumulative percentage of variance of the geochemical parameters, and the loadings for the varimatrix-rotated factor matrix, are presented in Table 3.

Table 3. Rotated factor loading matrix.

\begin{tabular}{|c|c|c|c|c|}
\hline Parameter & Factor 1 & Factor2 & Factor3 & Commonality \\
\hline $\mathrm{Cl}^{-}$ & $\mathbf{0 . 9 7 3}$ & -0.173 & 0.025 & 0.977 \\
\hline $\mathrm{Mg}^{2+}$ & $\mathbf{0 . 9 4 3}$ & -0.150 & 0.174 & 0.943 \\
\hline $\mathrm{TDS}$ & $\mathbf{0 . 9 3 4}$ & 0.076 & -0.088 & 0.885 \\
\hline Density & $\mathbf{0 . 9 3 3}$ & 0.042 & -0.068 & 0.877 \\
\hline $\mathrm{Na}^{+}$ & $\mathbf{- 0 . 8 1 8}$ & 0.211 & -0.369 & 0.849 \\
\hline $\mathrm{Ca}^{2+}$ & 0.056 & $\mathbf{- 0 . 7 7 8}$ & -0.071 & 0.614 \\
\hline $\mathrm{SO}_{4}{ }^{2-}$ & -0.306 & $\mathbf{0 . 7 5 8}$ & -0.202 & 0.709 \\
\hline $\mathrm{K}^{+}$ & 0.037 & 0.125 & $\mathbf{0 . 9 5 3}$ & 0.926 \\
\hline
\end{tabular}

The study area experiences high rates of evaporation, with an average evaporation rate of $3040 \mathrm{~mm} / \mathrm{a}$. As a result, the groundwater is very saline and is dominated by insoluble ions such as $\mathrm{Mg}^{2+}, \mathrm{Cl}^{-}$, and $\mathrm{Na}^{+}$. Evaporation of groundwater in the Qaidam Basin leads to sequential deposition of salt minerals of increasing solubilities. The minerals are thus precipitated in the following order: carbonate deposition, gypsum deposition, stone salt, sodium magnesium sulfate deposition, potassium-magnesium salt deposition, carnallite deposition, and bischofite deposition. In agreement, experimental results of evaporation and concentration of brine in the study area indicate that the order of mineral precipitation is as follows: alundum $\left(\mathrm{CaCO}_{3}\right)$, gypsum $\left(\mathrm{CaSO}_{4}\right)$, rock salt $(\mathrm{NaCl})$, thenardite $\left(\mathrm{Na}_{2} \mathrm{SO}_{4}\right)$ and bloedite $\left(\mathrm{Na}_{2} \mathrm{Mg}\left(\mathrm{SO}_{4}\right)_{2} \bullet 4 \mathrm{H}_{2} \mathrm{O}\right)$, sylvine $(\mathrm{KCl})$, carnallite $\left(\mathrm{KMgCl}_{3} \bullet 6 \mathrm{H}_{2} \mathrm{O}\right)$, bischofite $\left(\mathrm{MgCl}_{2} \cdot 6 \mathrm{H}_{2} \mathrm{O}\right)$ (Guo et al., 2008).

Factor 1 (FC1) explains 50.392\% of the total variance (Table 3). FC1 shows strong positive loading towards $\mathrm{Mg}^{2+}, \mathrm{Cl}^{-}$, density and TDS concentration of brine, as well as strong negative correlation with $\mathrm{Na}^{+}$concentration. This indicates that $\mathrm{Mg}^{2+}$ and $\mathrm{Cl}^{-}$are the dominant ions in the brine. The low correlation with $\mathrm{Na}^{+}$may demonstrate that the brine is undergoing mirabilite precipitation. Thus, FC1 may be associated with mirabilite precipitation due to the removal of $\mathrm{Na}^{+}$from the brine to form mirabilite. This can be expressed as the following formula:

$$
\mathrm{Na}^{+}+\mathrm{SO}_{4}{ }^{2-}=\mathrm{Na}_{2} \mathrm{SO}_{4} \downarrow
$$

Factor 2 (FC2) explains $19.256 \%$ of the total variance. FC2 showed strong positive loading towards $\mathrm{SO}_{4}{ }^{2-}$ and strong negative correlation with $\mathrm{Ca}^{2+}$, indicating that the brine is undergoing aragonite precipitation. At this stage, the concentration of $\mathrm{Ca}^{2+}$ is decreasing and the concentration of $\mathrm{SO}_{4}{ }^{2-}$ is increasing. Aragonite precipitates early during brine enrichment, due to its low solubility. Thus, FC2 may be interpreted as the decrease in $\mathrm{Ca}^{2+}$ during aragonite precipitation, as expressed by the following formula:

$$
\mathrm{Ca}^{2+}+\mathrm{CO}_{3}^{-}=\mathrm{CaCO}_{3} \downarrow
$$

Factor 3 (FC3) explains $12.045 \%$ of the total variance and had strong positive loading towards $\mathrm{K}^{+}$(Ye et al., 2015; Guo., 2015). Carbonate is the first mineral to precipitate from brine due to its low solubility, resulting in a relative increase of $\mathrm{K}^{+}$concentration in the brine. Thus, FC3 may be associated with the relative increase of $\mathrm{K}^{+}$during the early stages of salt precipitation. 


\subsubsection{Distribution analysis}

The common factor score for each sample point was calculated and the factor score spatial interpolation profile was plotted in Fig. 3. As demonstrated in Fig. 3, the precipitation of $\mathrm{Na}^{+}$is strongest (FC1) in the central northern part of the study area A (area, Fig 3a). Area A has a particularly shallow groundwater depth of $<5 \mathrm{~m}$, when compared with the brine depth interpolation diagram of the study area in Fig. 4. The groundwater in this location is also strongly affected by evaporation. Highest TDS values can be observed in area A (Fig. 4) and the evaporation and concentration of groundwater brine are also deep. Our results indicate that the highest degree of evaporation and highest rates of brine evolution are found in area A.

The south-eastern part of the study area (area B, Fig 3b) is most strongly affected by the precipitation of $\mathrm{Ca}^{2+}(\mathrm{F} 2)$, as can be seen in Fig. 3. The groundwater level in area B is low and buried deep (Fig. 4b). The evaporative concentration of groundwater brine is weak relative to area $\mathrm{A}$, indicating that the brine in area $\mathrm{B}$ is at an earlier stage of brine evolution.

The highest concentrations of $\mathrm{K}^{+}$can be observed in area $\mathrm{C}$ (Fig. 3c), and is located in an area of transition from low to high TDS values; increasing from the southeast to the centre of the lake. Area $\mathrm{C}$ does not extend into the maximum TDS area (area A), which is undergoing mirabilite precipitation and is thus close to the precipitation stage of potassium salt. The content of $\mathrm{K}^{+}$in area A is relatively stable and is therefore less affected by FC3.

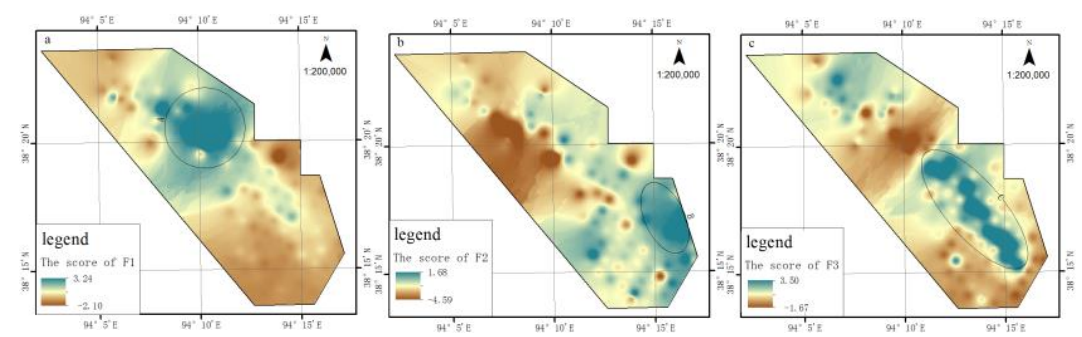

Fig. 3. Spatial variations of F1, F2 and F3. (a), (b) and (c) represent the factor score value of each groundwater samples for Factor 1, Factor 2 and Factor 3, respectively.

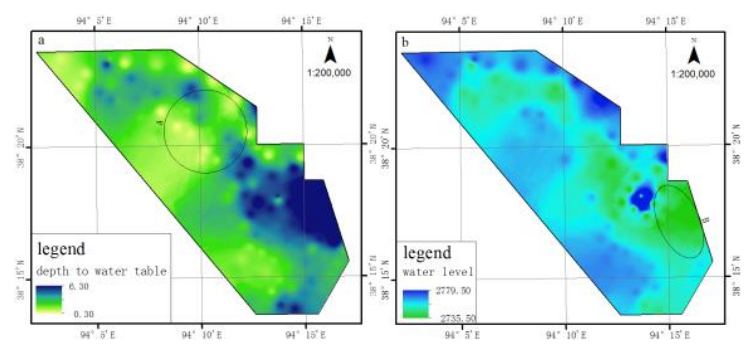

Fig. 4. The spatial variations of depth to water table and water level. (a) represent the spatial variations of depth to water table. (b) represent the spatial variations of water level.

\section{Conclusion}

Our results indicate that the highest degree of brine evolution occurs in the centre of Mahai Salt Lake (area A). The brine water level in the central part of the lake is relatively low and experiences high levels of evaporation and concentration, resulting in raised TDS values. The hydrochemical classification of brine in this area is $\mathrm{Cl}-\mathrm{Mg}$. The high concentrations of 
TDS and reduction of $\mathrm{Na}^{+}$suggests the centre of the lake is in the later stages of mirabilite precipitation.

TDS values increase from the southeast to the centre of the Salt Lake (area C). Throughout this transition, the brine is also evolving. The brine $\mathrm{K}^{+}$concentration gradually increases across this transition, towards the centre, in response to carbonate precipitation. The $\mathrm{K}^{+}$concentration stabilizes at the centre of the lake (area A - where TDS values are highest) as the brine reaches saturation and is close to the precipitation stage for potassium salts.

The authors acknowledge the support of the National Natural Science Foundation of China (41672243, 41877198).

\section{References}

1. S. Dogramaci, G. Skrzypek, W. Dodson, P.F. Grierson, Journal of Hydrology (Amsterdam), 475, 2012.

2. C.J. Eastoe, A. Long, L. S. Land, J.R. Kyle, Chemical Geology, 176, 1 (2001)

3. G. Han, C.Q. Liu, Chem Geol, 204, 1 (2004)

4. J. Luo, Y. An, Q. Wu, Earth and environment, 42, 03 (2014)

5. M.L. Wang, Beijing: Geology Publishing House, 2001.

6. Q. Zhao, S. Hu, J. Feng, Scientia Geographica Sinica, 37, 01 (2017)

7. S. Hu, C. Xiao, X. Liang, Chinese Geographical Science, 84 (2018)

8. Y. Bo, C. Liu, P. Jiao, Chemie der Erde - Geochemistry, 73, 3 (2013) 